\title{
Analysis of the 10kV Combined Overvoltage Protector Explosion
}

\author{
Si Yadong ${ }^{1}$, Lan Hongling ${ }^{1}$, Yang Jian ${ }^{1}$, Li Weinan ${ }^{1}$, Shi Jinyu ${ }^{1}$, Jiang Jun ${ }^{2}$, \\ Zhao Rui ${ }^{2}$ \\ ${ }^{1}$ Chaoyang Power Supply Company, Liaoning Electric Power Company Limited, State Grid, China, \\ ${ }^{2}$ Fushun Power Supply Company, Liaoning Electric Power Company Limited, State Grid, China, \\ fushunpowersupply@163.com
}

Keywords: Overvoltage protection; gap; Zinc oxide valve; Overvoltage

\begin{abstract}
The combined overvoltage protection is a new type of overvoltage protection devices. Its principle and performance are the same as conventional lightning arrester. It also has unique advantages. Phase combined over-voltage protection can limit the over-voltage between phase and earth. While it can limit the phase-phase overvoltage. This is an advantage not available in the traditional arrester. In the $10 \mathrm{kV}$ high voltage system phase combined overvoltage protection internal clearance under damp conditions. When electrical equipment is operating under over voltage, the phase modular overvoltage protector will explode. According to the three-phase modular overvoltage protection structure, combined with the power system, this paper proposes a transformation measures.
\end{abstract}

\section{Introduction}

Combined overvoltage protection is a new type of overvoltage protection device, as shown in Figure 1, Figure 2. Three phase modular overvoltage protection widely used in $10 \mathrm{kV}$ and $10 \mathrm{kV}$ below voltage power system. It can limit the lightning Over Voltage, vacuum breaker operation overvoltage, other transient overvoltage (power systems). It can effectively protect motors, transformers, switches, capacitors, cables, bus and other electrical equipment insulation, to avoid over-voltage damage. It also has unique advantages. Phase combined overvoltage protection can limit the overvoltage between phase and earth[1]. It can limit the phase - phase overvoltage. This is an advantage not available in the traditional arrester. Overvoltage protection device test, should be consistent with "DL / T 474.5-2006" field insulation test guidelines in section 5 (arrester test) requirements[2].

Combined overvoltage protection, mainly divided into two categories, namely, with the series gap of overvoltage protection, overvoltage protectors without gaps. The need to provide high-voltage frequency AC and high voltage DC power supply during project testing. There is no special test equipment to meet the testing requirements. It is necessary to develop a combined over-voltage protection integrated detection device (for $10 \mathrm{kV}$ and $10 \mathrm{kV}$ below the voltage level). The device is for combined over-voltage protection debugging and test projects. Application of the device can detect wet insulation inside the device, valves aging and other dangerous defects as soon as possible[3-5].

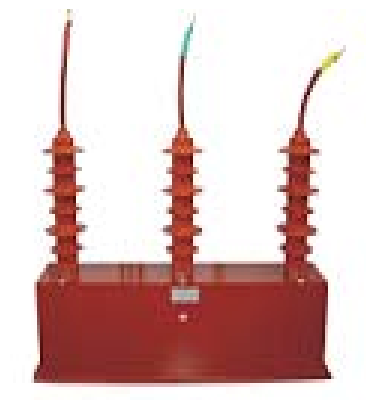

Fig.1 Three-phase combined voltage protection 


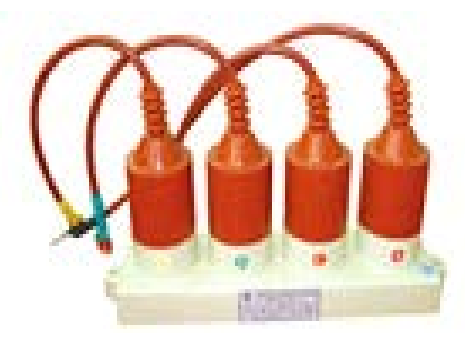

Fig.2 Four-phase combined voltage protection

\section{Combined over-voltage protection Accident Case}

(1)Circumstances of the incident

When the April 28, 2014 afternoon, the water company's water treatment system operators, to start the highpressure controlled cooling water pump, overvoltage protection (installed in 10kV high voltage cabinet) exploded.

(2)Cause analysis

Highvoltage switchgear open the cable compartment door.It found that over-voltage protection A, C phase lead completely blown. B phase wire Insulation burned. A, C phase zinc oxide valve and seal gap occurs completely burst. At the top position over-voltage protection gap, there are obvious traces of discharge. Through the examination of other overvoltage protection devices in the power distribution room, it is found that the internal clearance is affected with damp and deformation. Analyzing the reasons for the explosion, over-voltage protection gap due to the moisture, there are discharges, resulting zinc oxide valve aging. When the vacuum circuit breaker closes, and generates operating over voltage, so the overvoltage protection exploded.

\section{Structure analysis of three phase combined overvoltage protector}

The advantages of the three-phase combined overvoltage protector:

(1) Eliminate the chargeability of zinc oxide valve.

(2)The effective protection of transient over voltage (power frequency overvoltage, resonance overvoltage).The whole transient overvoltage is limited to the protection range. The zinc oxide valve is not damaged.

Inherent defects of three-phase combined overvoltage protector:

(1) The problem of gap seal. Due to technical reasons, the gap can not be sealed under vacuum. There may be a leak, causing moisture or moisture into the gap. Use sealant to seal the gap completely. Due to the presence of air gap between the air, long time discharge expansion will produce "adsorption moisture" phenomenon. The gap is affected with damp, which can lead to the aging of the zinc oxide valve sheet.

(2)Because of the existence of the gap, it is not suitable for 1mA DC voltage U1mA and $75 \% \mathrm{U} 1 \mathrm{~mA}$ leakage current test. It is only suitable for insulation resistance and power frequency discharge test. The principle of power frequency discharge test is to compare the average value of the three discharge voltage and the value of the factory. In the qualified range is normal. The zinc oxide valve must be carried out under the $75 \% \mathrm{U} 1 \mathrm{~mA}$ leakage current test, in order to determine whether the aging. This leads to the conclusion that the power frequency discharge test is qualified, even if the clearance of the overvoltage protection device is damp. In fact, the zinc oxide valve has long been aging. When the overvoltage is produced, the overvoltage protection device will explode, which brings great hidden trouble to the electric power system.

(3) When the four - star connection structure is adopted, it is required to set up a neutral point. This will make the operation of the valve plate unit changes, bring difficulties to the insulation.

(4) The phase - to - phase overvoltage protection, each of the valve plate units accounted for 1/2. When one phase is in trouble, the other is unable to bear all the phase voltage.

(5) For the operation reliability of the phase - phase valve plate unit, the protection level of the 
phase - to - ground overvoltage should be fully considered.

\section{Grounding mode analysis of $10 \mathrm{kV}$ system}

The water company uses the way is, $10 \mathrm{kV}$ grounding system neutral point through the small resistance grounding mode, is the so-called effective grounding method. This grounding mode features:

(1) The neutral point grounding resistance is an energy dissipation element. It is the damping element of the system resonance. Due to its significant damping effect, the system resonance overvoltage caused by various reasons can be eliminated.

(2) In the case of non symmetrical short circuit faults, the power frequency overvoltage of the non fault phase can be limited to 1.7 times. The multiple of transient overvoltage can be limited to 2.6 times. Because the fault time is very short, so the over-voltage protection device will not be a long time, to withstand the high power frequency overvoltage. Therefore, over voltage protection device is mainly used to prevent lightning type overvoltage and operation type overvoltage.

\section{Rectification measures}

(1)Replacement of overvoltage protector

The original series type over voltage protector, all replaced with no gap zinc oxide over-voltage protection device.The characteristics of the non gap zinc oxide over-voltage protection device:

1) The steep wave response characteristic is good, no chopped wave, and no adverse effect on the protection equipment.

2) no discharge delay, the response rate of the nanosecond.

3) The action is stable with no gap inherent defects. There is no problem of environmental impact in the absence of gap discharge.

4) The structure is simple and the technology is excellent. Easy to implement on line monitoring and preventive test, and has high reliability.

According to market research, the decision to use a new type of special six column full phase over voltage protector. This product is $\mathrm{Y} /$ delta six column gapless structure. All the zinc oxide components run independently, without interfering with each other. This type of overvoltage protection device can better suppress the lightning over-voltage and operating over voltage. A large capacity zinc oxide valve can be used to effectively reduce the number of thermal collapse accidents caused by over voltage energy exceeding the protection device. The 6 groups of zinc oxide valve are all sealed in the vacuum condition.

(2)Improvement of test method

The whole machine of the test equipment is controlled by the single chip microcomputer. Test equipment by the power circuit, high voltage DC circuit, power frequency inverter, power frequency boost, LCD display, button operation and other functional modules. Test equipment to meet the DC test, but also to meet the power frequency discharge test.

1) DC test

The first step, the DC 1mA reference voltage will be used to provide DC voltage for over voltage protector. The pulsating part of the DC voltage is not more than $\pm 1.5 \%$. When the current is stable in the $1 \mathrm{~mA}$, the value of the read voltage should not be less than the specified value in the specification.

The second step is measuring the leakage current value. Applying 0.75 times the DC $1 \mathrm{~mA}$ reference voltage to the over voltage protector. The pulsating part of the DC voltage is not more than $\pm 1.5 \%$.The current flowing through the overvoltage protector is not more than $50 \mathrm{~A}$.

2) AC test

Power frequency discharge test: Power frequency discharge test is for over voltage protector. Uniform boost from zero start, while observe the change of the current table. When the current meter has a sudden change, the protective device begins to discharge the action. The voltage at this time is the value of power frequency discharge voltage. After the discharge, it should be in the $0.2 \mathrm{~S}$ 
within the time to disconnect the power source. Each measurement interval is not less than 15 seconds. Measure three times, and get the average value. The average value should not be less than $85 \%$ of the parameter values specified in the specification.

\section{Conclusion}

Correct choice of over voltage protector technical parameters. The three-phase combined type zinc oxide over-voltage protection device (with series gap) is to strengthen the inspection and monitoring. Using infrared thermal imager to test the temperature is on a regular test. On line monitoring device is used for installing leakage current value. Application of the developed test equipment, such as regular overvoltage protection device is for the necessary tests. Ensure the safe and stable operation of the three-phase combined overvoltage protector.

\section{Reference}

[1] Ping Shaoxun, Zhou Yufang. Analysis of the neutral grounding operation of power system. China Electric Power Press, 2010

[2] Li Jinglu, Tan Qiong, Li Zhiqiang. Lightning protection technology for mountain power grid. China Power Press, 2011

[3] Xu Ying, Xu Shiheng. Overvoltage protection and insulation coordination in AC power system. China Power Press, 2006

[4] Baoding Tianwei Electric Co., Ltd. Transformer Test Technology. Machinery Industry Press, 2000

[5] Zhang Zhibao. Transformer Principles and Applications. Chemical Industry Press, 2007 